\title{
APPLICATION OF INVENTORY METHOD IN IMPROVING STUDENT LEARNING ACTIVITIES ON NATURAL RESOURCES SUMMARY AND ENVIRONMENTAL ENVIRONMENT Aqmarina Dewi
}

\author{
Setiawarga Primary School, Cimahi City, West Java, Indonesia \\ dewi_aqmarina@yahoo.com
}

\begin{abstract}
The main issues of this research are how to improve the learning activity of Elementary School students on Natural Resources (NR) and Environment (EN) subject matter through the method of discovery. The objectives of the research are as follows: (1). Increase the learning activity of elementary students through discovery method; (2). Provides learning through discovery methods that enhance learning activities. The methods / approaches used in achieving the following objectives: (a). Collect students and elementary teachers involved in research; $(B)$. Provide an overview of the research activities to be undertaken; $(C)$. Reflecting on, discussion of learning by method of discovery; (D). Collaborate with elementary teachers in the determination of experimental class and control class; (E). Implementation of learning method of discovery; $(F)$. Evaluation of learning by method of discovery. The results showed that there was an increase in learning activity of elementary school students through learning by inventory method of 34\%; (2). Elementary students are enthusiastic about learning by the method of discovery given by the teacher; (3). The occurrence of collaboration between one student and another student at the time of learning by the method of discovery is done.
\end{abstract}

Keywords: Learning Activity, Discovery Method.

\section{INTRODUCTION}

This research was conducted to find out the relationship between discovery method and student learning activity in improving learning for fifth grade students in elementary school (SD) especially on Natural Science (IPA) study considering that nowadays a lot of learning done in elementary school only by using lecture method Or demonstrations only.

Given that the curriculum of learning in schools now turns into a National Curriculum that refers to student-centered learning (Student Center), Teacher Center is not the only teacher and teacher as a classroom learning facilitator. In the national curriculum, students must further explore the learning or science based on the theme and the learning process should be done in real way so that the students gain direct experience in the learning process. As in the learning activities so many learning methods that we can do to make the students more interested in learning activities in elementary and exploring at home. Here the researchers will use one of the 
methods of learning that is the method of discovery to further explore the interest and learning activities of students on science learning.

Based on Law No.20 Year 2003 article 37 on Sisdiknas (2003), the curriculum of KTSP in science subjects in 2006 aims to make students have the following capabilities:

1. Know the concepts related to society and the environment.

2. Have basic skills for logical and critical thinking, curiosity, inquiry, problem solving, and skills in social life.

3. Have a commitment and awareness of social values and humanity.

4. Have the ability to communicate, work together and compete in a pluralistic society, local, national, and global. (Gunawan, 2011).

Referring to Law No.20 of 2003 on National Education System, researchers hope that science subjects in elementary school can be understood by students and can be actualized in everyday life by students with the method of discovery at school. The implementation of the discovery method is expected to enable students to use inductive reasoning to develop more enjoyable IPA learning.

Through the application of the method of discovery, it is expected that the 5th graders can improve their activities on understanding the Natural Resources and the Environment on learning. Based on the problems that developed above, this study focuses on the study"Application of Discovery Methods in Improving Student Activity on the subject of Natural Resources and Environment".

\section{A. Background Research}

The things underlying this research are based on general research data that has been previously disclosed and field observation records in general where the learning process in elementary school is still far from expectations that should be more enable students through activities that can find something new. In science learning in the classroom for example, often less meaningful learning process for students. Students just sit sweet and silent, listen to the teacher's explanation, many teachers stand in front of the class explain the subject matter, and teachers tend to be more active lectures themselves. There is also an indication that teacher pedagogy practices are less appropriate to the topic and do not have an appropriate focus so that experience, understanding does not develop optimally.

54 | Application of Inventory Method in Improving Student Learning Activities on Natural Resources Summary and Environmental Environment 
The 21st Century National Education Paradigm states that the strategy of achieving education in the future one of them is by applying different learning methods in elementary school. This method holds to the principle that each individual is unique and has their own talents, so the learning method must take into account the diversity of "learning style" of each individual. Through different learning activities through the use of this discovery method, students are expected to further develop their learning activities.

Learning models that emphasize these characteristics and diversity need to be developed. Examples of learning models in question include PBL (Problem Based Learning) and methods of discovery. In addition, emphasis should be placed on cooperative learning models between individuals to improve their interpersonal and social competence, such as: Cooperative Learning and Collaborative Learning through learning activities based on discovery methods.

The things that happened that have been expressed before can be understood as kemahluman that really happened in elementary school. Thus there is a need for mentoring and research that can provide examples of various learning with discovery methods so that students and teachers of the elementary school more excited and open to study harder. Through this research, we hope to find meaningful findings on the extent to which methods of discovery have been made to improve student learning activities. The specific problems we may face are the reluctance of students and elementary teachers to our presence, but through collaborative discussions, we are confident that this will be resolved and this research will provide deep meaning to all of us.

The method of discovery is a learning model based on the constructivism approach of Piaget and Vygotsky. Constructivism understands the essence of learning as a human activity of building or creating knowledge by trying to give meaning to knowledge according to experience (Nurohman: 2008).

The method of discovery is a model designed to engage students in digging information and inquiring, performing and finding, collecting data and analyzing and making their own inferences. In this model students are given the freedom in constructing thoughts and findings during the activity so that students do themselves without the burden, fun and high motivation so that learning will be more meaningful. The method of discovery of learning emphasizes the development of reasoning, model building, the interrelationship with real-world applications or daily life and can make students have direct experience, so as to overcome learning problems 
such as difficult recall of the subject matter (Starrett and Morcos, 2001); (Raviv Daniel, 2004); And (Atles and Ali, 2011).

Characteristics of the method of discovery are: independent, mutually supportive, happy, passionate learning, integrated learning, using multiple sources, active, fun, not boring, sharing with friends, critical and creative students. The method of discovery can also provide an in-depth appreciation of what is learned, so that what is obtained by students is not easily forgotten because students acquire such knowledge directly through their own experience. By learning the method of discovery, students can appreciate the concepts taught by the teacher, the students can prove facts and concepts, and also encourage the students 'curiosity in more depth, so it tends to arouse students' desire to conduct research to gain observation and experience in the scientific process. Through the method of discovery, students can also benefit from: increase interest, motivation, strengthen memories, can overcome the problem of learning difficulties, avoid misunderstandings, get feedback from students and connect the concrete and abstract. (Weinberg, Ithaca and Thomas, 2009) and (Ivers and Whitney, 2009).

In the implementation of learning with the method of this invention to be really effective need to pay attention to student learning activities. Discovery methods make learners become independent, dare to ask questions, explore curiosity and become creative learners. A teacher can and should be able to provide students with experience, at least ten minutes for students where students can feel, hear, see, and act on subjects to be taught for the rest of the time. This can create a fun atmosphere, reduce student boredom and learn more effectively.

\section{B. Formulation Of The Problem}

Based on the background that has been disclosed before, this research is directed to answer the problem as follows: "How Use of Discovery Method in Improving Student Activity of Primary School on the subject of Natural Resources and Environment?". Our problems are detailed through the following research questions:

1. Can the discovery method increase the learning activity of elementary students on the subject of natural resources and the environment?

2. How much is the improvement of the learning activity of elementary school students who are learning through the method of discovery? 


\section{Limitations of Research}

Based on the formulation of the problems that have been disclosed, it is necessary to limit the research to make this research more focused. The research limits are given as follows:

1. This research is limited to elementary school science lesson.

2. The subject of the research is the 5th grade elementary school students.

3. Learning is done through the use of learning by method of discovery.

4. Learning outcomes measured are student learning activities through the test of learning outcomes in the form of a description.

\section{Research Purposes}

The purpose of this study as follows:

1. To obtain an effective and efficient learning method that can improve the learning activity of elementary students.

2. To obtain the Student Worksheet (LKS) tool for learning of discovery methods developed to guide students for their learning activities to develop optimally.

3. To obtain an appropriate evaluation tool to be able to test the achievement of student learning activities through learning methods of discovery given.

4. To obtain information on the feasibility of the method of invention given in its implementation.

5. To facilitate the teacher in delivering the learning materials should be given by the method of discovery.

6. To direct elementary students in gaining more knowledge and experience through the study of discovery methods.

\section{E. Output Target}

The expected output target for this research activity is as follows:

1. Manual manual for mechanism of how to develop learning activity of discovery method in elementary school.

2. The results of research that can be used as material as data and facts when this activity is done, can be a material of further study for the material of final project completion (thesis) / research and can be published nationally through the available educational journals.

3. There is a follow-up research program for the next year of program development based on program evaluation, whether conducted by the monev team, or elementary school. 
4. As a study material, as for the follow-up research program that can be done as follows: the increase of students and teachers who do the learning with the method of discovery.

5. Increased understanding of learning at elementary school level for both students and teachers.

The greatest portion of science that students learn in school is not obtained through discovery, but is obtained through notices (by lecture / expository), reading, imitating, seeing, observing, and the like.

The method of discovery is one method of learning to find and discover on their own. Learning in this system the teacher presents the lesson material in the final form, but the students are given the opportunity to seek and find it themselves and use problem-solving techniques (Djamarah and Zain, 2002).Broadly speaking the procedure as follows:

1. Simulation

Teachers begin to ask questions by asking students to read / listen to the descriptions that contain the problem.

2. Stating the Problem

Students are given the opportunity to identify problems. Most chose it that was considered most attractive and flexible to solve. The selected problem must then be formulated in the form of a question / hypothesis, ie statement (statement) as a temporary answer to the question posed.

3. Data Collection

To answer the questions / prove whether or not this hypothesis is true, students are given the opportunity to collect (collect) various objects, interviews with resource person self-test and so on.

4. Data Processing

All reading, interview, observation, etc. information are all randomized, classified, tabulated, even where necessary in a certain way and interpreted at a certain level of need.

5. Verify

Proof based on the results of processing and interpretation / information that there is a statement / hypothesis that has been formulated earlier then checked, whether answered / no, whether proven or not. 


\section{Generalization}

The next stage based on student verification learns to draw certain conclusions / generalizations. According to Sudirman et al. (1991) that the method of discovery is a way of presenting a lesson involving many students in mental processes in the context of its discovery. Furthermore Ruseffendi (1991) explains that "the method (teaching) of discovery is a teaching method that governs teaching in such a way that the child acquires knowledge that he has not previously known through notification, partially or entirely found alone."

\section{METHODS}

In learning a lot of media that we can actualize in learning so that students can receive the subject matter well and fun. One of them is environmental media around.In order for learning to use the surrounding environment media can run smoothly it is necessary to have appropriate learning methods as a bridge so that students can receive the subject matter well and fun. One such method is the discovery method, in which students can find themselves the core of the learning process in the school and the teacher only provides reinforcement and concludes in the process of learning activities undertaken.

In addition Mulyasa (in Fate, 2012) states that discovery is a learning strategy that emphasizes direct experience in the field, without having to always rely on the theories of learning contained in the textbook guide. The researcher hopes that there is a correlation between the method of discovery with the current curriculum system, the national curriculum.The research will be carried out in several stages:

1. Planning.

2. Implementation.

3. Observation.

4. Reflection.

The subjects of this study are five odd semester students totaling as many as 35 people consisting of students 18 men and 17 female students held in SetiawargaCimahi School. The fifth grade was chosen as the subject of the study because the students needed immediate action to improve student activity and learning outcomes by applying the discovery learning approach with surrounding environmental media. 
The study was conducted in two cycles so that there will be significant results. In each cycle the study consists of two meetings, one meeting for the implementation of learning and one meeting for the test of learning outcomes. The method used in data collection in this study is a test method that is carried out at the end of the cycle by using the test of learning outcomes to know the improvement of science learning outcomes. The test used is a written test. In this study the instrument used is the test of learning outcomes in the form of multiple choice tests.

For the purposes of collecting data related to the observer's task, the researcher and the partner researcher determine the necessary data collection techniques:

1. Observation Technique

Observations used are direct observation so as to know the actual state of the class and observe the activities of teachers and students during the learning process takes place.

2. Techniques

The test is done to find out the students' understanding on natural science subject matter of natural appearance.

3. Data Analysis Techniques

Data processing is a research effort to summarize accurately the data that has been collected in a form that can be trusted and true. Data that have been collected by both researchers and partner researchers will be processed and analyzed qualitatively-descriptive.

\section{RESULTS AND DISCUSSION}

This research activity has been carried out in SDN Setiawarga Kota Cimahi and produced some findings that fit the title of "Use of MP to Improve Student Activity of Primary School on Natural Resources and LH subject". As described in the previous chapter, this study aims to improve the activity of Primary School students through the learning of MP. Results and outcomes achieved in this study as follows.

Research findings obtained in the form of findings of research activities of student learning activities and interviews. The findings are further analyzed and interpreted.

\section{A. Student Learning Activity Result Data}

The data obtained to determine student learning outcomes in the form of preliminary and final tests. Initial test is done to determine the students 'initial ability before the MP learning is given and the learning result obtained in the final test is used as a comparison to know the

60 | Application of Inventory Method in Improving Student Learning Activities on Natural Resources Summary and Environmental Environment 
students' success in following the learning using MP. Initial test result data are presented in the following table:

Table 1

Research Data of Comparative Class (Demonstration Method)

\begin{tabular}{|c|c|c|c|c|c|c|}
\hline \multirow{2}{*}{ No } & \multicolumn{2}{|c|}{ Value } & \multicolumn{2}{|c|}{ Percentage } & \multirow{2}{*}{ Gain $(\%)$} & \multirow{2}{*}{$\begin{array}{l}\text { Student } \\
\text { Group }\end{array}$} \\
\hline & Pretes & Postes & Pretes $(\%)$ & Postes (\%) & & \\
\hline 1 & 0,50 & 2,50 & 5,0 & 25,0 & 20,0 & Low \\
\hline 2 & 0,75 & 2,50 & 7,5 & 25,0 & 17,5 & Low \\
\hline 3 & 1,00 & 2,50 & 10,0 & 25,0 & 15 & Low \\
\hline 4 & 1,00 & 5,50 & 10,0 & 55,0 & 45 & Low \\
\hline 5 & 1,50 & 7,00 & 15,0 & 70,0 & 55 & Low \\
\hline 6 & 1,50 & 4,25 & 15,0 & 42,5 & 27,5 & Low \\
\hline 7 & 1,75 & 3,25 & 17,5 & 32,5 & 15 & Low \\
\hline 8 & 1,75 & 5,50 & 17,5 & 55,0 & 37,5 & Low \\
\hline 9 & 1,75 & 6,25 & 17,5 & 62,5 & 45 & Low \\
\hline 10 & 2,00 & 5,50 & 20,0 & 55,0 & 35 & Medium \\
\hline 11 & 2,00 & 5,50 & 20,0 & 55,0 & 35 & Medium \\
\hline 12 & 2,25 & 6,00 & 22,5 & 60,0 & 37,5 & Medium \\
\hline 13 & 2,25 & 8,25 & 22,5 & 82,5 & 60 & Medium \\
\hline 14 & 2,50 & 4,00 & 25,0 & 40,0 & 15 & Medium \\
\hline 15 & 2,50 & 2,75 & 25,0 & 27,5 & 2,5 & Medium \\
\hline 16 & 2,75 & 3,75 & 27,5 & 37,5 & 10 & Medium \\
\hline 17 & 2,75 & 6,50 & 27,5 & 65,0 & 37,5 & Medium \\
\hline 18 & 3,00 & 4,75 & 30,0 & 47,5 & 17,5 & Medium \\
\hline 19 & 4,50 & 1,75 & 45,0 & 17,5 & $-27,5$ & Medium \\
\hline 20 & 4,75 & 8,25 & 47,5 & 82,5 & 35 & Medium \\
\hline 21 & 5,25 & 6,25 & 52,5 & 62,5 & 10 & Medium \\
\hline 22 & 5,25 & 8,50 & 52,5 & 85,0 & 32,5 & Medium \\
\hline 23 & 5,50 & 5,25 & 55 & 52,5 & $-2,5$ & Medium \\
\hline 24 & 5,75 & 6,00 & 57,5 & 60,0 & 2,5 & Medium \\
\hline
\end{tabular}




\begin{tabular}{|c|c|c|c|c|c|c|}
\hline \multirow{2}{*}{ No } & \multicolumn{2}{|c|}{ Value } & \multicolumn{2}{|c|}{ Percentage } & \multirow{2}{*}{ Gain $(\%)$} & \multirow{2}{*}{$\begin{array}{l}\text { Studen } \\
\text { Group }\end{array}$} \\
\hline & Pretes & Postes & Pretes $(\%)$ & Postes (\%) & & \\
\hline 25 & 5,75 & 6,00 & 57,5 & 60,0 & 2,5 & Medium \\
\hline 26 & 5,75 & 7,25 & 57,5 & 72,5 & 15 & Medium \\
\hline 27 & 6,00 & 9,50 & 60,0 & 95,0 & 35 & Medium \\
\hline 28 & 6,00 & 9,50 & 60,0 & 95,0 & 35 & Medium \\
\hline 29 & 6,25 & 5,75 & 62,5 & 57,5 & -5 & Medium \\
\hline 30 & 6,25 & 8,50 & 62,5 & 85,0 & 22,5 & High \\
\hline 31 & 6,25 & 7,00 & 62,5 & 70,0 & 7,5 & High \\
\hline 32 & 6,25 & 7,75 & 62,5 & 77,5 & 15,0 & High \\
\hline 33 & 6,25 & 6,75 & 62,5 & 67,5 & 5,0 & High \\
\hline 34 & 6,50 & 7,25 & 55,0 & 72,5 & 7,5 & High \\
\hline 35 & 7,00 & 8,00 & 50,0 & 80,0 & 11,0 & High \\
\hline & Avarag & & 30,0 & 35,0 & 30,0 & \\
\hline
\end{tabular}

Table 2

Data of Class MP Study Results

\begin{tabular}{|c|c|c|c|c|c|c|}
\hline \multirow{2}{*}{ No } & \multicolumn{2}{|c|}{ Vakue } & \multicolumn{2}{|c|}{ Percentage } & \multirow{2}{*}{ Gain $(\%)$} & \multirow{2}{*}{$\begin{array}{l}\text { Student } \\
\text { Group }\end{array}$} \\
\hline & Pretes & Postes & Pretes (\%) & Postes (\%) & & \\
\hline 1 & 1,50 & 5,50 & 15 & 55 & 40,0 & Low \\
\hline 2 & 2,20 & 6,25 & 22 & 62,5 & 40,5 & Low \\
\hline 3 & 2,70 & 9,50 & 27 & 95,0 & 68,0 & Low \\
\hline 4 & 3,00 & 7,00 & 30 & 70,0 & 40,0 & Low \\
\hline 5 & 3,00 & 7,75 & 30 & 77,5 & 47,5 & Low \\
\hline 6 & 3,00 & 8,25 & 30 & 82,5 & 52,5 & Low \\
\hline 7 & 3,00 & 8,50 & 30 & 85,0 & 55,0 & Low \\
\hline 8 & 3,00 & 8,00 & 30 & 80,0 & 50,0 & Low \\
\hline 9 & 3,20 & 9,00 & 32 & 90,0 & 58,0 & Low \\
\hline 10 & 3,20 & 6,75 & 32 & 67,5 & 35,5 & Low \\
\hline 11 & 3,20 & 8,50 & 32 & 85,0 & 53,0 & Medium \\
\hline 12 & 3,20 & 9,75 & 32 & 97,5 & 65,5 & Medium \\
\hline
\end{tabular}




\begin{tabular}{|c|c|c|c|c|c|c|}
\hline \multirow{2}{*}{ No } & \multicolumn{2}{|c|}{ Vakue } & \multicolumn{2}{|c|}{ Percentage } & \multirow{2}{*}{ Gain $(\%)$} & \multirow{2}{*}{$\begin{array}{l}\text { Studen } \\
\text { Group }\end{array}$} \\
\hline & Pretes & Postes & Pretes $(\%)$ & Postes (\%) & & \\
\hline 13 & 3,50 & 9,00 & 35 & 90,0 & 55,0 & Medium \\
\hline 14 & 3,50 & 8,00 & 35 & 80,0 & 45,0 & Medium \\
\hline 15 & 3,50 & 8,75 & 35 & 87,5 & 52,5 & Medium \\
\hline 16 & 3,70 & 9,75 & 37 & 97,5 & 60,5 & Medium \\
\hline 17 & 3,70 & 9,75 & 37 & 97,5 & 60,5 & Medium \\
\hline 18 & 4,00 & 9,50 & 40,0 & 95,0 & 55,0 & Medium \\
\hline 19 & 4,00 & 9,00 & 40,0 & 90,0 & 50,0 & Medium \\
\hline 20 & 4,25 & 8,50 & 42,5 & 85,0 & 42,5 & Medium \\
\hline 21 & 4,25 & 8,00 & 42,5 & 80,0 & 37,5 & Medium \\
\hline 22 & 4,50 & 9,00 & 45,0 & 90,0 & 45,0 & Medium \\
\hline 23 & 4,75 & 8,00 & 47,5 & 80,0 & 32,5 & Medium \\
\hline 24 & 4,75 & 8,00 & 47,5 & 80,0 & 32,5 & Medium \\
\hline 25 & 4,75 & 7,50 & 47,5 & 75,0 & 27,5 & Medium \\
\hline 26 & 4,75 & 9,25 & 47,5 & 92,5 & 45,0 & Medium \\
\hline 27 & 5,00 & 8,25 & 50,0 & 82,5 & 32,5 & Medium \\
\hline 28 & 5,00 & 9,00 & 50,0 & 90,0 & 40,0 & Medium \\
\hline 29 & 5,00 & 8,75 & 50,0 & 87,5 & 37,5 & Medium \\
\hline 30 & 5,50 & 9,00 & 55,0 & 90,0 & 35,0 & Medium \\
\hline 31 & 5,50 & 9,25 & 55,0 & 92,5 & 37,5 & High \\
\hline 32 & 6,00 & 9,00 & 60,0 & 90,0 & 30,0 & High \\
\hline 33 & 6,25 & 9,50 & 62,5 & 95,0 & 32,5 & High \\
\hline 34 & 6,25 & 9,25 & 62,5 & 92,5 & 30,0 & High \\
\hline \multirow[t]{2}{*}{35} & 6,50 & 9,75 & 75,0 & 97,5 & 42,5 & High \\
\hline & & Avarage & 60,0 & 95,0 & 70,0 & \\
\hline
\end{tabular}

Based on the above table, the average score of the initial test obtained by the comparator class (MD) is 30 with the highest score of 60 and the lowest 5, whereas the MP class the average score of the initial test 60 with the highest value of 75 and the lowest 10 . After tested 
statistically, The average score of the initial class tests of MD with the MP class, the comparison is not much different and the second homogeneous test score score, it indicates that the initial ability of the two classes before the treatment is given is the same.

Based on the above table, the average score of the final test obtained by the MD class students is 30 with the highest score of 70 and the lowest of 15, while the average grade of the final test score is 95 with the highest score of 98 and the lowest 50. If compared between the average score The final test of the two classes, the final grade of MP is bigger than the MD class.

The class gain scores of MD and MP classes were obtained from the difference between the initial test result and the final test. Based on the above table, the average gain score of the class of MD is 30 with the highest value of 50 and the lowest -27.5 , while the average gain of the MP class is 55 with the highest value of 78 and the lowest 37 . When compared between the average score of the second gain Class, average score gain of MP class is bigger than class of MD. This indicates that there is an increase in learning outcomes and student learning activities in the MP class that use learning-based discovery method as a learning method.

\section{B. Statistical Test Results}

This statistical test was conducted to determine the difference of learning outcomes between the classes that were given the lesson using the MP with the class that was given the $\mathrm{MD}$ lesson as the comparison class. Test results for final score as follows:

Table 3

Analysis of Learning Outcomes of MD Class and Class of MP Students of Low Group

\begin{tabular}{|c|c|c|}
\hline \multirow[t]{2}{*}{ No. } & \multicolumn{2}{|l|}{ \%Gain } \\
\hline & MD Class & MP Class \\
\hline 1 & 20,0 & 40,0 \\
\hline 2 & 17,0 & 40,5 \\
\hline 3 & 15,0 & 68,0 \\
\hline 4 & 45,0 & 40,0 \\
\hline 5 & 55,0 & 47,5 \\
\hline 6 & 27,0 & 52,5 \\
\hline 7 & 15,0 & 55,0 \\
\hline 8 & 37,0 & 50,0 \\
\hline 9 & 20,0 & 58,0 \\
\hline
\end{tabular}

64 | Application of Inventory Method in Improving Student Learning Activities on Natural Resources Summary and Environmental Environment 


\begin{tabular}{crr}
\hline No. & \multicolumn{2}{c}{$\%$ Gain } \\
\cline { 2 - 3 } & MD Class & MP Class \\
\hline 10 & 35,0 & 35,5 \\
\hline Avarage & 20 & 50 \\
\hline
\end{tabular}

There is a significant difference in learning outcomes between low-grade students in the MD class and the MP class. MP learning can increase the percentage of students' low group learning outcomes from $20 \%$ to $50 \%$.

Table 4

Analysis of Learning Outcomes MD Class and Class MP Student Group Medium

No. \%Gain

\begin{tabular}{|c|c|c|}
\hline & MD Class & MP Class \\
\hline 1 & 35,0 & 53,0 \\
\hline 2 & 37,0 & 65,5 \\
\hline 3 & 60,0 & 55,0 \\
\hline 4 & 15,0 & 45,0 \\
\hline 5 & 2,5 & 52,5 \\
\hline 6 & 10,0 & 60,5 \\
\hline 7 & 37,5 & 60,5 \\
\hline 8 & 17,5 & 55,0 \\
\hline 9 & $-27,5$ & 50,0 \\
\hline 10 & 35,0 & 42,5 \\
\hline 11 & 10,0 & 37,5 \\
\hline 12 & 32,5 & 45,0 \\
\hline 13 & $-2,5$ & 32,5 \\
\hline 14 & 2,5 & 32,5 \\
\hline 15 & 2,5 & 27,5 \\
\hline 16 & 15,0 & 45,0 \\
\hline 17 & 30,0 & 32,5 \\
\hline 18 & 35,0 & 40,0 \\
\hline 19 & $-5,0$ & 37,0 \\
\hline
\end{tabular}




\begin{tabular}{crr}
\hline No. & \multicolumn{2}{c}{$\%$ Gain } \\
\cline { 2 - 3 } & MD Class & \multicolumn{1}{c}{ MP Class } \\
\hline 20 & 22,0 & 35,0 \\
\hline Avarage & 20,0 & 45,0 \\
\hline
\end{tabular}

There was a significant difference in learning outcomes between the moderate group students in the MD class and the MP class. MP learning can increase the percentage of students' learning outcomes in moderate groups from $20 \%$ to $45 \%$.

Table 4

Analysis of Learning Outcomes of Class of MD and Class of High Student Group of Students

\begin{tabular}{crr}
\hline No. & \multicolumn{2}{c}{$\%$ Gain } \\
\cline { 2 - 3 } & & \multicolumn{2}{c}{$\begin{array}{c}\text { Hypertext } \\
\text { Class }\end{array}$} \\
\hline 1 & 7,5 & 37,5 \\
\hline 2 & 15,0 & 30,0 \\
\hline 3 & 5,0 & 32,5 \\
\hline 4 & 7,5 & 30,0 \\
\hline 5 & 10,0 & 32,0 \\
\hline Avarage & 10,0 & 30,0 \\
\hline
\end{tabular}

There is a significant difference in learning outcomes between high group students in the MD class and the MP class. MP Learning can increase the percentage of high student learning outcomes from $10 \%$ to $30 \%$.

Table 5

Analysis of Classroom Learning Results of MD and Class MP No.

$\%$ Gain

\begin{tabular}{rrr}
\cline { 2 - 3 } & \multicolumn{1}{c}{ MD Class } & \multicolumn{1}{c}{ MP Class } \\
\hline 1 & 20,0 & 40,0 \\
\hline 2 & 17,5 & 40,5 \\
\hline 3 & 15,0 & 68,0 \\
\hline 4 & 45,0 & 40,0
\end{tabular}


P-ISSN: 2580-9326

E-ISSN: 2580-7714
Journal of Elementary Education

Volume 1, Number 1, September 2017

\begin{tabular}{|c|c|c|}
\hline \multirow[t]{2}{*}{ No. } & \multicolumn{2}{|c|}{ \%Gain } \\
\hline & MD Class & MP Class \\
\hline 5 & 55,0 & 47,5 \\
\hline 6 & 27,5 & 52,5 \\
\hline 7 & 15,0 & 55,0 \\
\hline 8 & 37,5 & 50,0 \\
\hline 9 & 45,0 & 58,0 \\
\hline 10 & 35,0 & 35,5 \\
\hline 11 & 35,0 & 53,0 \\
\hline 12 & 37,5 & 65,5 \\
\hline 13 & 60,0 & 55,0 \\
\hline 14 & 15,0 & 45,0 \\
\hline 15 & 2,5 & 52,5 \\
\hline 16 & 10,0 & 60,5 \\
\hline 17 & 37,5 & 60,5 \\
\hline 18 & 17,5 & 55,0 \\
\hline 19 & $-27,5$ & 50,0 \\
\hline 20 & 35,0 & 42,5 \\
\hline 21 & 10,0 & 37,5 \\
\hline 22 & 32,5 & 45,0 \\
\hline 23 & $-2,5$ & 32,5 \\
\hline 24 & 2,0 & 32,5 \\
\hline 25 & 2,0 & 27,5 \\
\hline 26 & 15,0 & 45,0 \\
\hline 27 & 35,0 & 32,5 \\
\hline 28 & 35,0 & 40,0 \\
\hline 29 & $-5,0$ & 37,5 \\
\hline 30 & 22,5 & 35,0 \\
\hline 31 & 7,5 & 37,5 \\
\hline 32 & 20,0 & 30,0 \\
\hline
\end{tabular}




\begin{tabular}{crr}
\hline \multirow{2}{*}{ No. } & \multicolumn{2}{c}{$\%$ Gain } \\
\cline { 2 - 3 } & MD Class & \multicolumn{2}{c}{ MP Class } \\
\hline 33 & 5,0 & 52,5 \\
\hline 34 & 7,5 & 30,0 \\
\hline 35 & 10,0 & 32,5 \\
\hline Avarage & 20,0 & 54,0 \\
\hline
\end{tabular}

There is a significant difference in learning outcomes between the MD classes and the MP classes. MP learning can increase the percentage of learning outcomes from $20 \%$ to $54 \%$.

\section{Obtained Outside}

From the results of research activities that have been implemented in SDN Setiawarga Kota Cimahi obtained some outcomes according to the plan that has been described in the previous chapter. The results are as follows:

\begin{tabular}{rlr}
\multicolumn{2}{c}{ Table 6 } \\
Research Survey \\
\hline No. & \multicolumn{1}{c}{ Output type } & Indicator \\
\hline 1 & Scientific publications in journals & Accepted \\
\hline 2 & Publication on mass media (print / electronic) & Draft \\
\hline 3 & Improved understanding and skills of the community & Done \\
\hline 4 & Services, models, social engineering, systems, products / goods & Done
\end{tabular}

Outcomes that have been implemented as described above are activities to increase understanding and skills of society and services, models, social engineering, systems, products / goods through activities to elementary school teachers in SDN Setiawarga. The next release is scientific publication in the journal / proceedings which will be published in September 2017 to the Journal of Primaryedu STKIP Siliwangi Bandung.

In addition to the outcomes that have been delivered, there are several outpourings among them as follows:

1. The data of other research results can be used as material as data and facts for the material of final project completion (thesis) / research and can be published. 
2. There is a follow-up program for the next year of program development based on program evaluation, whether conducted by the monev team or SD.

3. Increased students and elementary school teachers who are doing MP learning.

4. Increased understanding of learning at elementary level for students, as well as teachers.

\section{CONCLUSION}

Based on the results of research conducted in SDN Setiawarga Kota Cimahi, it can be concluded things as follows:

1. Learning MP can improve student learning activities Primary elementary school on natural resources and environment.

2. Increased student learning outcomes of the MP class is greater than the MD class (34\%) and there are significant differences in learning outcomes among each group of students.

\section{ACKNOWLEDGMENTS}

Lead researcher Tim would like to thank a lot to Independent Research, Setiawarga Elementary School for the trust given, and RamdhanWitarsa, M.Pd.As a mentor in elementary school education STKIP Siliwangi Bandung. We will keep our trust and mother confidence and will continue to develop in future studies.

\section{REFERENCES}

Ahamed, Y., Macdonald, H., Reed, K., Naylor, P. J., Liu-Ambrose, T., \& McKay, H. (2007). School-based physical activity does not compromise children's academic performance. Medicine and Science in Sports and Exercise, 39(2), 371-376.

Barros, R. M., Silver, E. J., \& Stein, R. E. K. (2009).School recess and group classroom behavior. Pediatrics, 123, 431-436.

Basch, C.E. (2010). Healthier students are better learners: A missing link in school reforms to close the achievement gap. Research Review (6), 1-107.

Beets, M. W., Patton, M. M., \& Edwards, S. (2005). The accuracy of pedometer steps and time during walking in children. Medicine and Science in Sports and Exercise, 37(3), 513-520.

Bricker, D., Yovanoff, P., Capt, B., \& Allen, D. (2003).Use of a curriculum-based measure to corroborate eligibility decisions. Journal of Early Intervention, 26, 20-30.

Cardon, G., De Clercq, D., De Bourdeaudhuij, I., \&Breithecker, D. (2004). Sitting habits in elementary schoolchildren: A traditional versus a "Moving school". Patient Education and Counseling, 54(2), 133-142.

Centers for Disease Control and Prevention.(2010). Association between school-based physical activity, including physical education, and academic performance. Atlanta, GA: Author. 
Centers for Disease Control and Prevention.(2009). Physical activity for everyone. Retrieved March 23, 2012 from http://www.cdc.gov/physicalactivity/everyone/guidelines/index.html

Chomitz, V. R., Slining, M. M., McGowan, R. J., Mitchell, S. E., Dawson, G. F., \& Hacker, K. A. (2009). Is there a relationship between physical fitness and academic achievement? Positive results from public school children in the Northeastern United States. Journal of School Health, 79, 30-37.

Coe, D. P., Pivarnik, J. M., Womack, C. J., Reeves, M. J., \&Malina, R. M. (2006). Effect of physical education and activity levels on academic achievement in children. Medicine and Science in Sports and Exercise, 38(8), 1515-1519.

Della Valle, J., Dunn, K., Dunn, R., Geisert, G., Sinatra, R., \&Zenhausern, R. (1986).The effects of matching and mismatching students' mobility preferences on recognition and memory tasks. Journal of Educational Research, 79(5), 267-272.

Erwin, H. E., Abel, M. G., Beighle, A., \& Beets, M. W. (2009).Promoting children's health through physically active math classes: A pilot study.Health Promotion Practice, 12(2), 244- 251.

Erwin, H. E., Beighle, A., Morgan, C. F., \& Noland, M. P. (2011).Effect of a low-cost, teacherdirected classroom intervention on elementary students' physical activity. Journal of School Health, 81, 455-461.

Fedewa, A.L., \&Ahn, S. (2011). The effects of physical activity and physical fitness on children's cognitive outcomes: A meta-analysis. Research Quarterly for Exercise and Sport, 82(3), 521-535.

Foegen, A., Jiban, C., \&Deno, S. (2007). Progress Monitoring Measures in Mathematics: A Review of the Literature. Journal of Special Education, 41(2), 121-139.

Fredericks, C. R., Kokot, S. K., \&Krog, S. (2006). Using a developmental movement programme to enhance academic skills in grade 1 learners. South African Journal for Research in Sport, Physical Education, and Recreation, 28(1), 29-42.

Gamst, G., Myers, L. S., \&Guarino, A. J. (2008). Analysis of variance designs: A conceptual and computational approach with SPSS and SAS. New York, NY: Cambridge University Press.

Gibson, C. A., Smith, B. K., Dubose, K. D., Greene, J. L., Bailey, B. W., Williams, S. L., et al. (2008). Physical activity across the curriculum: Year one process evaluation results. International Journal of Behavioral Nutrition and Physical Activity, 5, 36.

Jitendra, A. K., Sczesniak, E., \&Deatline-Buchman, A. (2005).An exploratory validation of curriculum-based mathematical word problem solving tasks as indicators of mathematics proficiency for third graders. School Psychology Review, 34, 358-371.

Liu, A. L., Hu, X. Q., Ma, G. S., Cui, Z. H., Pan, Y. P., Chang, S. Y., et al. (2007). Report on childhood obesity in China (6) evaluation of a classroom-based physical activity promotion program. Biomedical Environmental Science, 20(1), 19-23.

Lowden, K., Powney, J., Davidson, J., \& James, C. (2001). The class moves! Pilot in Scotland and Wales: University of Glasgow.

Macdonald, H. M., Coupe, D. M. L., Kontulainen, S. A., \& McKay, H. A. (2007). A schoolbased physical activity intervention positively affects change in Imax in pre- and early pubertal boys. Journal of Bone and Mineral Research, 22, S12-S12. 
Macdonald, H. M., Kontulainen, S. A., Petit, M. A., Beck, T. J., Khan, K. M., \& McKay, H. A. (2008). Does a novel school-based physical activity model benefit femoral neck bone strength in pre- and early pubertal children? Osteoporosis International, 19(10), 14451456.

Macy, M.G., Bricker, D.D., \& Squires, J.K. (2005). Validity and reliability of a curriculumbased assessment approach to determine eligibility for Part C services. Journal of Early Intervention, 28(1), 1-16.

Maeda, J. K., \& Randall, L. M. (2003). Can academic success come from five minutes of physical activity? Brock Education Journal, 13(1), 14-22.

Mahar, M. T., Murphy, S. K., Rowe, D. A., Golden, J., Shields, A. T., \&Raedeke, T. D. (2006).Effects of a classroom-based program on physical activity and on-task behavior. Medicine and Science in Sports and Exercise, 38(12), 2086-2094.

National Center for Health Statistics.(2009). Health, United States, 2008. Hyattsville, MD: U.S.

Department of Health and Human Services.Norlander, T., Moas, L., \& Archer, T. (2005). Noise and stress in primary and secondary school children: Noise reduction and increased concentration ability through a short but regular exercise and relaxation program. School Effectiveness and School Improvement, 16(1), 91- 99.

Ogden, C. L., Yanovski, S. Z., Carroll, M. D., \&Flegal, K. M. (2007).The epidemiology of obesity.Gastroenerology, 132, 2807-2102.

Pangrazi R,,Beighle A, \&Pangrazi D. (2009). Promoting physical activity and health in the classroom. San Francisco, CA: Pearson Benjamin Cummings.

Pate, R.R., Davis, M. G., Robinson, T. N., Stone, E. J., McKenzie, T. L., \& Young, J. C. (2006).Promoting physical activity in children and youth: A leadership role for schools. Circulation, 114, 1214-1224. Pretti-Frontczak, K.L. (2002). Using curriculum-based measures to promote a linked system approach. Assessment for Effective Intervention, 27(4), 15-21.

Reschly, A.L., Busch, T.W., Betts, J., Deno, S.L., \& Long, J.D. (2009). Curriculum-based measurement oral reading as an indicator of reading achievement: A meta-analysis of the correlational evidence. Journal of School Psychology, 47, 427-469.

Sibley, B. A., \&Etnier, J. L. (2003). The relationship between physical activity and cognition in children: A meta-analysis. Pediatric Exercise Science, 15, 243-256.

Stecker, P. M., \&Lembke, E. S. (2005).Advanced applications of CBM in reading: Instructional decision making manual. Retrieved March 20, 2010 from http://www.studentprogress.org/library/Training/CBMmath/AdvancedReading/AdvRdg Manual - FORMATTEDSept29.pdf

Stevens, T. A., To.Y., Stevenson, S. J., \&Lochbaum, M. R. (2008). The importance of physical activity and physical education in the prediction of academic achievement. Journal of Sport Behavior, 31, 368-388.

Stewart, J. A., Dennison, D. A., Kohl, H. W., \& Doyle, J. A. (2004). Exercise level and energy expenditure in the TAKE 10! in-class physical activity program. Journal Of School Health, 74(10), 397-400.

Strong, W. B., Malina, R. M., Blimkie, C. J. R., Daniels, S. R., Dishman, R. K., Gutin, B....Trudeau, F. (2005). Evidence based physical activity for school-age youth. Journal of Pediatrics, 146, 732-737. 
Troiano, R. P., Berrigan, D., Dodd, K. W., Masse, L. C., Tilert, T., \& McDowell, M. (2008).Physical activity in the United States measured by accelerometer. Measurement and Science in Sports and Exercise, 40, 181-188.

Trudeau, F. \& Shephard, R.J. (2010).Relationships of physical activity to brain health and the academic performance of schoolchildren.American Journal of Lifestyle Medicine, 4, 138150.

Uhrich, T. A., Swalm, R. L. (2007). A pilot study of a possible effect from a motor task on reading performance. Perceptual and Motor Skills, 104, 1035-1041

Vincent, S. D., \&Pangrazi, R. P. (2002). Determining baseline physical activity levels in children. Medicine and Science in Sports and Exercise, 14, 432-441.

World Health Organization.(2009). Global Strategy on diet, physical activity and health. Retrieved March 10, 2012 from http://www.who.int/dietphysicalactivity/childhood/en/ 